\title{
Mobile learning for teacher professional learning: benefits, obstacles and issues
}

\author{
Peter Aubusson $^{\mathrm{a} *}$, Sandy Schuck ${ }^{\mathrm{a}}$ and Kevin Burden ${ }^{\mathrm{b}}$ \\ ${ }^{a}$ Centre for Research in Learning and Change, University of Technology, Sydney, Australia; \\ ${ }^{b}$ Centre for Educational Studies, The University of Hull, Hull, UK
}

(Received 14 January 2009; final version received 21 July 2009)

\begin{abstract}
This paper reflects on the role of mobile learning in teachers' professional learning. It argues that effective professional learning requires reflection and collaboration and that mobile learning is ideally suited to allow reflection-inaction and to capture the spontaneity of learning moments. The paper also argues for the value of collaborations between teachers and students in professional learning. It suggests that authentic artefacts and anecdotes, captured through mobile technologies, can enable the sharing, analysis and synthesis of classroom experiences by teachers and students. Such analysis and synthesis helps to encourage collaborative reflective practice and is likely to improve teacher and student learning as a result. Ethical issues that might arise through using mobile technologies in this way are also discussed. Teacher voice is presented to indicate the range of views about mobile learning and to indicate current practices. Practical, school systemic, attitudinal and ethical factors may inhibit mobile technology adoption; these factors need to be researched and addressed to realise the potential of teacher mobile professional learning.
\end{abstract}

Keywords: mobile learning; professional learning; teaching; education

\section{Introduction}

Mobile devices are becoming ubiquitous. This ubiquity and ease of access suggests that their use for mobile learning would be valuable for both students and teachers. In general, information and communication technologies (ICT) have the potential to enhance teachers' professional learning by optimising opportunities for access to current educational information and experiences as well as providing opportunities for teachers to analyse, and collaboratively reflect on, their own practice. In particular, new technologies for collaborative learning provide rapid access to other viewpoints and balance the isolationist tendencies of the profession. Yet, in practice, transformational effects of such technologies for teacher professional learning are not systemic and are under-researched. Much of the current research investigates the integration of ICT into school curricula (Bain 2004; Staples, Pugach, and Himes 2005; HartnellYoung and Heym 2008) or their use for student learning (McHale 2005; Partnership for 21 st Century Skills 2005). Where the use of ICT by teachers is investigated, it is generally to examine how teachers can be better prepared to use ICT in their teaching, rather than in their own learning (Downes et al. 2001). Yet without teacher

\footnotetext{
*Corresponding author. Email: peter.aubusson@uts.edu.au
} 
professional learning that enables opportunities for critical reflection and access to changing knowledge, effective teacher use of information technologies in their classrooms is likely to be limited.

The slow adoption of such technologies by teachers has been noted with concern by governments and employing authorities worldwide (Peck, Cuban, and Kirkpatrick 2002; Schuck 2002; Phelps, Graham, and Kerr 2004). One possible reason for such slow adoption is that teachers' work environments inhibit connectedness; they are literally and physically disconnected. They operate in environments where opportunities to learn occur in diverse and isolated places at unpredictable times. Unlike other professionals, teachers are itinerant. They do not tend to be located in one place for the working day, but move between classrooms, playgrounds and staffrooms. The nature of their workplace contexts suggests that mobile learning would be a most appropriate way for teacher professional learning to occur.

This paper argues for the need to re-examine teacher use of technologies for their own professional learning. In particular, we focus on mobile learning. Sharples, Taylor, and Vavoula (2005) describe the features of mobile learning as follows: it is learning that takes place "on the move", that occurs in a variety of places and times, and that capitalises on the ubiquitous nature of mobile technologies. These features align well with teachers' work contexts.

The sections that follow reflect on the role of mobile learning in teachers' professional learning and growth in two countries, Australia and the UK. We argue that effective professional learning requires reflection and collaboration and that mobile learning is potentially well suited to allow reflection-in-action, rather than just reflection-on-action (Schön 1987) and to capture the spontaneity of learning moments. Further, the ability to capture and share such moments provides opportunity for authentic examples of classroom experiences to be deconstructed. The paper also argues for the value of collaborations between teachers and students in professional learning, and suggests that artefacts captured through the use of mobile technologies enable sharing of learning experiences with a goal of improving the classroom learning environment. However, we note that these opportunities are not yet fully recognised by the teaching profession in either country, and are only sporadically evident in actual use. Examples of current teacher use of mobile technologies to enhance their own learning in the two countries are examined, as well as ethical issues that might arise through using mobile technologies in this way.

\section{Collaborative and mobile teacher learning}

Career-long professional learning is essential for teachers operating in today's complex world due to the rapid pace of change in knowledge (Clarke and Hollingsworth 2002; Guskey 2002; Grundy and Robison 2004). Research indicates that collaboration is critical for effective professional learning (Clement and Vandenberghe 2000; Burbank and Kauchak 2003; Aubusson et al. 2007). These authors note that the process of collaborative learning promotes critical reflection on practice and acknowledges teachers as active learners and producers of knowledge. Teachers' practical wisdom is central to their professional knowledge landscape (Connelly and Clandinin 1997). Practical wisdom is "a sense of what will 'work' and what will not. It is a capacity, in the first place for synthesis rather than analysis" (Berlin, cited by Hargreaves 1997, 409). Teachers exchange practical wisdom and test its veracity in discussions with others, often sharing their knowledge in the form of stories and 
anecdotes. The sharing of these stories develops their professional knowledge (Noddings and Witherell 1991). However, often these stories are limited to exchanges among small groups in individual school departments. Sometimes, teachers do not wish to expose their problems to school colleagues (Schuck 2003) and such sharing of stories and experiences benefits from access to supportive professionals outside of the school culture.

Mobile learning appears to be ideally suited to teachers as it provides a process of learning for professionals who differ from others in the contexts and ways in which they work and learn. Teachers do not spend large amounts of time at a desk, tending to be largely itinerant in their daily work. Collaborative learning has to take place on the move, in snatched moments, and requires the rapid exchange of anecdotes and stories with a wide, diverse community. The value of harnessing the power of mobile technologies lies in their capacity to generate collaborative professional learning involving reflection, production, synthesis and analysis. Mobile learning enables interactions with people both beyond and within one's own school; provides access to expertise over a range of areas readily available in an online learning environment; and builds personal and professional support networks. It capitalises on the ubiquitous nature of mobile technologies and their ease of use in a variety of locations (Sharples, Taylor, and Vavoula 2005).

However, research on mobile technologies and mobile learning in education has focused primarily on student learning, and on the ways that teachers can support that learning (see for example, Swan, van 't Hooft, and Kratcoski 2005). Very little research has been conducted on how teachers themselves might learn with these new technologies, or indeed with any digital technologies (Naismith et al. 2004; Fisher, Higgins, and Loveless 2006). One recent small-scale study (Wishart 2009) with six teachers and six trainee teachers found that the aspects of the mobile technologies that were valued by the users were the calendar, an ability to find information on the Internet using a search engine, and a capacity to take photographs or audio-record. The use for learning through a reflective blog and a capacity to communicate with others were hardly utilised.

Given the importance with which reflection by teachers is viewed (Biggs 2003), tools which might aid in that reflection deserve attention. Brookfield (1988) suggests that reflection should be seen as systematic rather than to solve specific problems. Richert (1992) emphasises the importance of dialogue in reflection. Priest and Sturgess (2005) argue for the importance of group reflection. Mobile technologies would appear to be ideal tools for encouraging reflection through their capacity for easy communication of ideas, and ways to clarify thoughts through interaction. However, this perception seems at odds with Wishart's (2009) findings above.

Fisher, Higgins, and Loveless (2006) argue that if different approaches to learning and teaching, and different relationships between students and teachers are to occur, it is essential to understand teachers' learning and the role that digital technologies might play in this. This paper seeks to build on the Fisher, Higgins, and Loveless review (2006) of teacher learning with digital technologies by considering what mobile learning, with its characteristics of being personal and portable (Naismith et al. 2004) and also collaborative, might contribute to this area. The paper focuses on teacher mobile learning involving shared professional conversations informed by digitally captured classroom events. In addition, it introduces a discussion about the ethical issues that might arise through teacher learning with mobile technologies, 
given the capacity of such technologies to capture, display and share classroom activities.

\section{Methodology}

\section{Participants}

The authors interviewed eight educators, comprising teachers, teacher advisors and teacher developers, to include an element of teacher voice in the paper. The eight research participants were selected because they are stakeholders in influencing professional learning and/or engagement with information and communication technology among teachers in schools. Pseudonyms have been used to ensure confidentiality. Short descriptions of the participants are provided here to establish their credibility as informants in the field under study. However, details are limited to ensure anonymity:

- Mark is a science teacher in an Australian secondary school. His responsibilities include providing professional learning for early career teachers. For about three years he has been using mobile devices, including his mobile phone, to capture audio, images and video in his classes.

- Pat is an Australian principal who has for many years been responsible for providing and promoting professional learning in her own schools and groups of schools. In her doctoral thesis she focused on her own practices and experiences with teachers in professional learning.

- Rebecca has responsibility for promoting technology to enhance teaching and learning in a state employing authority in Australia. She has overseen the development and provision of many professional learning programs targeting ICT in teaching and learning.

- Simon is the manager of a city learning centre (CLC) in the UK working closely with teachers to support their use and integration of technology into the classroom. He is currently working with a group of teachers who are exploring the potential value of mobile learning devices in their classroom prior to a larger roll-out of the technology.

- Dean is an advisory teacher for ICT working with secondary teachers at a city learning centre in the north of England. He recently ran a pilot for two large secondary schools exploring the use of hand-held devices and the implications for curriculum change.

- Chris is an independent mobile learning consultant based in London. He works extensively with primary, secondary and tertiary teachers to support and extend their use of mobile technologies in learning.

- Michael is an educational software developer who specialises in designing and developing software for mobile devices and mobile learning in the classroom. He has worked with a large number of teachers in the classroom to design applications for mobile devices.

- Helen is the ICT co-ordinator at a large secondary school in the north of England. She participated in a university course focused on the use of mobile learning in schools and developed materials using her mobile device for the GCSE Diploma Digital Applications (DiDA).

This range of participants with their extensive experience in professional learning and/ or teacher uptake of technology serves as the data source for this study. 


\section{Data collection}

A semi-structured interview schedule focused on participant views of, or experiences with, mobile technologies; the ways in which they are used in professional learning; and current policies, ethical issues and influences that promote or hinder mobile professional learning. Guiding questions included:

- Are you aware of any cases of professional learning where mobile technology has been use? Can you tell us about these? What happened? Why do you think this occurred?

- Do you think there is a place for mobile technology in teacher professional learning? Can you explain why you hold this view?

- What do you think would help create (or helped create) opportunities for mobile teacher professional learning? What things do you think hinder(ed) it? What policies might influence mobile teacher professional learning?

- We are particularly interested in mobile teacher learning which involves teachers in digitally capturing classroom events to share with other teachers to stimulate professional conversations. What ethical issues does it raise? How might they be addressed? What advice would you give to teacher leaders in the field about mobile professional learning? Are you aware of any policies that might prevent or promote this type of activity by teachers? What is your view of these policies?

The questions acted as a guide to target the research aims but the interview progressed as conversation where both interviewer and interviewee engaged in a dialogue about ideas, comments, stories and episodes recounted. Interviews ranged in length from 40-90 minutes.

\section{Data analysis}

The phenomenon under study was the actual and potential use of mobile technology in teacher professional learning. The analysis sought to explicate and interpret the participants' views, perceptions and understanding of this phenomenon. The research team collaboratively analysed the data obtained from interviews by coding, memoing and using the constant comparative method (Bogdan and Biklen 1992). The analysis was guided by "a ladder of analytical abstraction" to establish an interpretive framework for the phenomenon under study (Miles and Huberman 1994, 92). This process is particularly appropriate in early explorations of emerging practices. This system of analysis constructs a map formalising key elements of the phenomenon and indicates how they are connected and may influence each other (Miles and Huberman 1994). Coding proceeded in stages through discussion of instances among researchers until the agreed elements could survive re-testing against the data set.

The three main themes reported in this paper concern:

(1) Teachers' personal use of mobile devices in professional learning

- for their own learning

- for reflection

- for collaboration

- $\quad$ for support of staff development 
(2) Shared use of mobile devices among teachers and students

- for collaboration and feedback

- for celebrating students' work and achievements

(3) Ethics of use in the classroom

- for capture and transmission

- involving consent

\section{Teachers' personal use of mobile devices in professional learning}

Mark, an Australian teacher, used his mobile phone to video, audio record and photograph student role-plays in his science classes. He started using the mobile device because "it was there, in his pocket". He argued that its size and portability made it easy to use and less obtrusive than other modes of recording. Mark had a number of purposes for using the device in his classroom: one was for his professional learning, in that the record of the activity allowed him the opportunity to reflect on what had occurred, and indicate how engaged the students had been. A second use was to celebrate the work that students had completed.

According to Rebecca, an Australian leader in teacher development with ICT, this level of usage is probably unusual. "Teachers are slow adopters of technology and while teachers are mobile workers, specially in secondary school ... I think the step of making professional learning mobile hasn't really occurred yet. Perhaps when they get their own laptops and other devices, I think these will be enablers of that". This person indicated that such usage was unlikely in the near future. Given the current demographic profile, she felt that the shift towards sophisticated usage of mobile devices for purposes other than personal communication may be a generation of teachers away. "We have teachers who have never actually activated their email account and never even sent [an email] message."

This observation was echoed by Chris, an independent mobile learning consultant in the UK, who noted how rarely teachers considered using their mobile devices for their own professional learning needs. In his experience working with teachers, most started by exploiting the students' natural interest in technology, “... adopting the practice of using the device to capture practice but by proxy, encouraging the students to do the work of the teacher." These views are supported by Wishart (2009) who found that teachers in her study did not use their PDAs to aid reflection and professional learning.

On the other hand, Rebecca estimated that there are $10 \%$ of high-end users who use mobile phones to contact students and receive assignments. "I think mobile professional learning is coming but the high priority now is in terms of their own teaching practice." She indicated that it would be essential to provide a scaffold to show teachers how to use mobile technologies for their own learning if mobile learning is to occur. Her experience indicated that widespread engagement with the tool as part of one's everyday activities would encourage teachers to start using mobile phones for their own learning. This view is supported by research by Kearney and Schuck (2006), which indicated that teachers became interested in particular technologies and their value in the classroom after they had become familiar with the technology for personal use. Kearney and Schuck saw that teachers who used digital video in their classes usually started experimenting with digital home videos and quickly saw the potential of the tool for their teaching and learning. A similar outlook appears to characterise the teachers interviewed in the UK with many of them alluding to the 
critical importance of personal ownership of the device itself. Most of the participants in the UK projects which we interviewed were required to use a separate hand-held device rather than their own personal mobile. As one teacher [Simon] noted "Until teachers can combine their own device with a work one they will continue to use two devices which is counterproductive."

Pat, an Australian school executive with a long-term role in teacher professional learning noted that she did not know any teachers who were engaged in mobile learning of this nature. "They don't know how to go about doing it, they see mobile phones as [personal] communication devices - that's very different from teaching devices." When asked about the potential for capturing classroom events and using these for reflective conversations, she responded "No. For teachers, reflection is just not part of the teaching culture. Nothing in the school system sets an expectation that you reflect on your practice." Her view was that mobile learning based in reflection would not be very effective because the reflective process is not part of the culture. "However, teachers are likely to record and photograph things but as a record of something that happened rather than for professional learning." Although teacher education programs emphasise reflection as an essential part of professional learning, as do policy documents about quality teaching (for example, see the NSW Teaching Standards which include a "capacity to reflect critically" (NSWDET n.d., 12)), Pat's perception that schools do not tend to be sites of teacher reflection is supported by Wishart's small-scale study (2009).

The above data indicate that participants see potential in mobile learning but there are clear obstacles, not the least of which include slow adoption of technology and a culture yet to embrace shared reflection in collaborative professional learning.

In a number of examples, advisory teachers and consultants in the UK reported the emerging use of mobile technologies for the sharing and dissemination of good practice, captured as part of advanced skills teachers outreach activities. Advanced Skills Teachers (ASTs) are a relatively recent development in the UK and have a specific remit to share and disseminate their own expertise and the practice they observe outside of their own classroom. In this study, the ASTs reported on using the mobile technology provided as part of a pilot scheme to capture examples of performance in both music and physical education (PE). These captured performances form the basis of professional dialogues enabling the ASTs to illustrate their discussions with other colleagues as part of the process of collaborative professional development.

Mark discussed his use of his phone in staff development, where he shows student activities to others, in particular early career teachers. He does this to indicate how to go about setting up an activity. For example, he used short video clips to show teachers how to do a role play. The captured episodes were easily shared and served as stimuli for professional discussion for teachers.

Another example of use for staff development was discussed in a blog by Australian linguist, Aidan Wilson, who noted that while there were few computers available in remote regions of Australia, mobile phones were plentiful. He is working with colleagues at the University of Sydney Pacific and Regional Archive for Digital Sources in Endangered Cultures to develop an indigenous mobile phone dictionary so that indigenous language speakers will be able to access their mother tongue, while non-native speakers will be assisted in working with communities in remote areas (Gibson 2008).

Although some of those interviewed identified practices and benefits associated with mobile professional learning, the view remains that mobile learning has been 
embraced by relatively few. This may in part be due to limited perceptions of devices they possess. Pat noted: "Although they have mobile phones but - they don't think about them as a mobile learning device and they don't have another (purpose built) mobile device. When it actually starts to occur more in classes it could be a trigger for using phones more and more in professional learning". Here Pat not only reminds us that mobile learning is not yet part of mainstream professional learning but also that teacher use of mobile technologies for their learning might flow from its use for student learning.

\section{Teachers and students using mobile devices collaboratively}

Students working in partnership with the teacher may use mobile technologies to critically review and collaboratively reflect on lessons. For example, Mark noted how his students were encouraged to take their own photos and videos in science lessons. "The students were allowed to video the solenoid working, using their own phones. They also can take snippets of the role plays and look at those. The main purpose here is for them to get something out of it."

Another purpose could be to place the student as a critical friend of the teacher, and allow the teacher to see their teaching from another perspective. However, although a number of reports suggest that mobile phones could be used more extensively in schools, this is not yet a widely accepted position, even within a single country such as the UK (McFarlane, Rouche, and Triggs 2007; Hartnell-Young and Heym 2008). Nevertheless, such partnerships are beginning to appear. One interviewee, Helen, an advisory teacher working in an English city learning centre (CLC), cited an example in a secondary school where pupils worked alongside their teachers to record classroom activities for later analysis. "Pupils were doing some work on migration and the students filmed the lesson using their SmartPhones and then they did the critical review at the end of it, which included reviewing how the teacher had put it across..." This type of practice would appear to be relatively rare. As Chris notes in his interview, it requires a particular pedagogical approach which "facilitates the students taking on the teacher role using the technology: analyzing, critiquing practice. The teachers' role has to shift to be less of a threat and more of a peer learner with their students.'

Mark also used the mobile phone to celebrate students' achievements in class. He would photograph the models that students had constructed or photograph the students engaged in a role-play and then download and print the photographs to place on the classroom wall. Students enjoyed this process and gained a sense of achievement. It also provided students with an opportunity to explain what they had done; gave the teacher a sense of how well the activity had worked; and allowed students the chance to take their own photographs of the aspects of the task they thought important. It works well because "it is a valuing of their work and celebrates what they do".

\section{Ethics of use in the classroom}

The use of mobile technologies by teachers for their own professional learning is not unproblematic. There are particular ethical issues including:

- Cyber-bullying

- Potential public access to events and materials intended for a limited audience 
- Sharing of digital materials for professional purposes

- Archiving and record keeping

- Parental and student informed consent

One challenge that can arise from students' capture and dissemination of classroom activities is that the video can be used to cyber-bully other students. A survey of 2611 year 8 and year 10 students suggests that online bullying is seen as a problem by about $15 \%$ of the respondents (Sharples et al. 2008). Even given her extremely liberal and positive support for pupil use of mobile devices to capture both their own, and her, practice, Helen also noted the problems she sometimes faces: "For part of my project I encouraged my Y11 DiDA pupils to use their devices in my lessons to take video, images and record audio clips. I encountered some social problems, which were to do with the maturity of the pupils rather than the capability of the technology. For example when using their devices to take video and images, some pupils decided to video one particular pupil on YouTube..." Where a teacher encourages use of mobile devices in the classroom there is a responsibility for the teacher to play an educative role to prevent cyber-bullying.

One of the key differences among those interviewed related to the risk of information intended for a limited audience becoming publicly distributed. For some, this had to be managed upfront because the view was that the distribution was almost impossible to control without certainty. In contrast, those who were more relaxed about digital recording considered that the distribution could be controlled and managed. However there was broad consensus that dissemination to a wider audience without permission is unethical.

Prior to the digital age, sharing artefacts for professional purposes was acceptable. For example, the exchange of photographs among students and staff was seen as normal because they were non-digital and such artefacts did not have the potential to be easily and quickly disseminated to a much larger audience. If mobile learning activities become part of the modern professional's normal working habits, should this absolve them from the need to gain parental permission in order to show and discuss teaching moments with others? Once there is a potential for material to be distributed digitally, even if the teacher has no intention of doing so, it raises the question of whether parental and child permissions are required.

One of the interviewees audio recorded lessons on a regular basis to listen to after the lesson so that he could reflect on how to improve his teaching. He recounted that on one occasion "students were being nasty to each other and I reached into my pocket and switched it [the mobile phone] on and recorded it". He then played back the recording to them so they could hear what they sounded like, in the expectation that they would make judgments about whether their behaviour was appropriate. While the surreptitious use may raise ethical questions, in this case, students and parents had given permission for recordings to be made in that class at the beginning of the year, and the purpose was to raise student awareness of appropriate behaviour. The authors believe that where such a recording is shared only with the participants in the event, it may be ethical. However, it may become unethical if shared with others, as it then has the potential to do harm to those participants. This raises further questions about the ethical nature of sharing this material with other staff members in order to seek advice on how best to manage such situations. 
One interviewee suggested that there was some similarity between what might occur in a class and what might occur in a doctor's practice. For example, a doctor might share a patient's records with a specialist to assist in diagnosis. Similarly a "teacher might use records ... (captured) on a mobile device to use in consultation with trusted colleagues about how to deal with something. But the material would have to be destroyed immediately after. Provided the use is clearly understood and agreed to, it's useful to have diagnosis done by second trusted people. If students objected then that would have to be respected" (Rebecca, interview). Thus critical elements involved in determining what is ethical depends on the level of confidence one has in the professionalism of others. Here for example, the implicit distinction is made between sharing with colleagues one trusts, to serve the needs of the learner, in contrast with sharing for another purpose with colleagues who might be less trustworthy. Further if there is an agreement to destroy records immediately after they have been used for their designated purpose this reduces the risk of unethical use.

The immediacy and spontaneity of capturing live events, using a mobile device in classrooms - features of the devices which we have identified as potential powerful learning agents for professionals - was also seen as a potential problem in some of the schools we interviewed. Dean, for example, emphasised the restrictions, both real and imagined, which are placed on teachers who might wish to capture aspects of their practice spontaneously: "It has to be a pre-arranged and agreed activity. So for example, you wouldn't get a teacher filming through a window a teacher doing an experiment ... It's all agreed in advance ... there is the fear factor - the YouTube fear factor as we call it here - where is it going to go [the video] once it has been done ?" Although we might expect logistical challenges to stand in the way of an entirely spontaneous use of the technology one might suspect there are also ethical concerns and worries preventing teachers from embracing the full potential of these technologies for their own professional learning.

It seems that policy development and school bureaucracies have struggled to keep pace with the potential benefits and harm that may arise from use of mobile devices in schools. There are four levels of consent that appear to arise in these examples of use of mobile devices to capture and share classroom events for professional learning: the first level is where no consent is sought and surreptitious recordings are made; the second level is where students and parents give a generic consent to use of such recordings throughout the year for the teacher's and students' learning; the third level occurs where consent is gained for specific types of incidents; and the fourth level is where permission is granted by students and parents and/or teachers for particular instances to be recorded. The authors cannot think of any case where use at the first level might be regarded as appropriate. As well, the fourth level is likely to be impractical given that the power of the learning is likely to occur from the spontaneity of the event. We believe that levels two and three may be considered ethical in some limited circumstances. These may include being used strictly for professional learning, not being disseminated beyond the professional learning community within the school, and ensuring that the purposes for the use are very clearly described in the consent letter. If the teacher wished to share the material beyond the school, perhaps because they did not have access to appropriate professional support within their school, strict protocols would need to be observed and explained to ensure the material was not abused. 


\section{Discussion}

This paper discusses the potential use of mobile technologies for professional learning. A small group of stakeholders were interviewed to provide insights and concerns of teachers and teacher leaders. However, while stakeholders spoke from their experience in working with larger groups of teachers, the views presented here cannot be taken as representative of all teachers. While not arguing for the generalisability of these views, we suggest that they will have trustworthiness because of their recognisability by the reader (Guba and Lincoln 1981).

Despite the apparent benefits and potential learning gains for teacher professionals, the adoption and actual use of mobile technologies by teachers appears to be unfulfilled at the present moment. Three areas of interest deserve special attention and further investigation. These are discussed below with comparisons and differences between the two national contexts highlighted where appropriate:

(1) the ethics of using mobile devices for professional learning;

(2) the degree to which most teachers are digitally competent and confident;

(3) the degree to which the teaching is a reflective profession.

Mobile technologies are potentially spontaneous capture and recording devices. Compared to traditional camcorder and camera technologies they are infinitely more portable and unobtrusive. They enable professionals to capture instances of their practice, for reflection and dissemination, in ways that normal cameras prohibit. At the cost of some loss in picture and audio quality (e.g. the lack of tripod support) they provide 'always connected' availability providing professionals with tools to deepen their own understanding of the teaching craft. We are suggesting that the use of such technologies by teachers and students can add to the learning of students and teacher alike. We argue for the value of student collaboration with teachers. Mobile technologies can be used to provide artefacts that provide varied perspectives of activities and starting points for extended discourse between students and teachers. We suggest that teachers can learn from students' perspectives and that students gain from deconstructing teaching moments with their teachers, so that they can see the rationale for teacher actions. Hence this paper argues for a genuine partnership between students and teachers in the capturing of learning moments, and a triangulation of learning experiences from the different viewpoints. Thomson and Gunter $(2006,839)$ discuss processes they used to work with school students to develop a "'student's eye' set of evaluative categories' and suggest that the process of viewing students as researchers can be both transformative and disruptive. Given that genuine reframing of practice often benefits from disruption, this process is likely to be valuable for teacher learning. As well, Cook-Sather (2006) suggests that acknowledging and listening to student voice indicates a position in which students are seen as active participants in their own learning. While this partnership might well be challenging for teachers, it would be likely to encourage students to work with, rather than subversively against, the teacher.

However, in both countries, the ethical questions arising from such use appears to be a stumbling block to mobile professional learning. At present these devices, in the hands of students, are generally seen as subversive and illicit tools (Hartnell-Young and Heym 2008). The use of mobile technologies by students in classrooms does not always further the learning experience of either students or teachers. Students furtively capturing and sharing video of the teacher through their handheld mobile 
devices, for dissemination on the web, is often done with the aim of embarrassing or humiliating the teacher. The UK press is littered with examples and criticisms from teachers (and some parents) and the violation of what they also see as their privacy when pupils have used mobile devices to record and post activity from the classroom, often surreptitiously (BBC News 2008). In one example, teachers at one school were incensed to discover pupils had posted a short video of an unruly class to YouTube. When approached by the school, YouTube refused to remove it, on the grounds that while "it portrayed the school in a bad light, it was not illegal" (Hartnell-Young and Heym 2008, 18).

In the UK, such issues are reducing the potential spontaneity of any learning to such an extent that it resembles choreographed recordings. This did not seem to be an issue for a teacher using a mobile device in the Australian context, where generic consent was sought from parents at the beginning of the teaching year. However, none of the Australian educators interviewed were at all certain of the protocols that might apply to digital capture of audio or images including students, though they were aware that these must not be made public.

The interviews support the literature which indicates that teachers are not embracing ICT for their own learning. While the reasons underlying this might be varied, teacher developers charged with encouraging teacher learning with ICT felt that a large number of teachers are resistant to use of ICT for professional learning. We have indicated that possible reasons could include the context of teacher workplaces with a general lack of connectivity and a view that sharing of stories is best done face-to-face rather than through a machine. In both cases, mobile learning would appear to be one way of overcoming these obstacles.

Some of the evidence collected (particularly in the Australian examples) suggested reflection was not a tool or characteristic valued by the profession in practice. If this is indeed the case, efforts to encourage the use of mobile technologies for reflection as part of professional learning, are unlikely to receive widespread support. These may be purely anecdotal claims with little or no generalisable significance. However, they may indicate a significant issue for the profession which will need to be addressed before mobile technologies can be fully effective. The importance and value of reflectivity for professional practice has been emphasised already and these claims are transferable across a range of similar professions. Indeed Benner (1996), referring to the nursing profession, has identified reflection as the essential ingredient in liberating practitioners as professionals by enabling them to build upon their 'experiential practical knowledge' in order to construct 'experiential theoretical knowledge', the cornerstone of professional learning. The degree to which this quality and practice is embedded within the teaching profession, therefore, is crucially important but not yet clear in either the Australian or UK contexts.

\section{Conclusion}

Our argument in this paper is that mobile technologies have the capacity to add new dimensions to teacher professional learning. Mobile learning provides an unrealised opportunity for the facilitation of observation, critique and sharing of activities in the classroom. There is an important knowledge production and knowledge sharing capacity afforded by mobile learning as the audience to a critical incident is able to be much broader than the teachers in the staffroom or the local region. The ability to share events and deconstruct them with a large number of critical friends suggests that 
feedback will be more extensive. In addition, asking students to be co-researchers, both capturing moments and using them to indicate what learning they felt was occurring in that moment, has tremendous power for teacher learning. While potentially risky and challenging, if teachers are able to use such feedback constructively, much learning can occur for both student and teacher. The strength of this kind of learning lies in its spontaneity, immediacy, honesty and agility.

Teachers could well be liberated by the technology. They could feel empowered by their partnership with students if they are prepared to work alongside their students and allow them to use their mobile phones as learning tools rather than subversive technologies. However, we caution that ethical issues will arise that require new ways of thinking about records of experience and question whether the teaching profession (and wider community) is ready to embrace this professional learning facilitated by evocative, powerful but intrusive m-technologies.

\section{References}

Aubusson, P., F. Steele, L. Brady, and S. Dinham. 2007. Action learning in teacher learning community formation: Informative or transformative? Teacher Development 11, no. 2: $133-48$.

Bain, A. 2004. Secondary school reform and technology planning: Lessons learned from a ten year school reform initiative. Australasian Journal of Educational Technology 20, no. 2: $149-70$.

BBC News Report. 2008. http://news.bbc.co.uk/1/hi/education/7156326.stm.

Benner, P.E. 1996. Expertise in nursing practice: Caring, clinical judgment, and ethics. New York: Springer

Biggs, J. 2003. Teaching for quality learning at university: What the student does. 2nd edition. Berkshire: SRHE \& Open University Press.

Bogdan, R.G., and S.K. Biklen 1992. Qualitative research for education. 2nd edition. Boston, MA: Allyn \& Bacon.

Brookfield, S. 1988. Developing critically reflective practitioners: A rationale for training educators of adults. In Training educators of adults: The theory and practice of graduate adult education, ed. S.D. Brookfield, 317-38. New York: Routledge.

Burbank, M., and D. Kauchak. 2003. An alternative model for professional development: Investigations into effective collaboration. Teaching and Teacher Education 19, no. 5: 499-514.

Clarke, D., and H. Hollingsworth. 2002. Elaborating a model of teacher professional growth. Teaching and Teacher Education 18, no. 8: 947-67.

Clement, M., and R. Vandenberghe. 2000. Teachers' professional development: A solitary or collegial adventure? Teaching and Teacher Education 16, no. 1: 81-101.

Connelly, M., and Clandinin, J. 1997. Teachers' personal practical knowledge on the professional knowledge landscape. Teaching and Teacher Education 7, no.13: 665-74.

Cook-Sather, A. 2006. Sound, presence and power: "Student Voice" in educational research and reform. Curriculum Inquiry 36, no. 4: 359-90.

Downes, T., A. Fluck, P. Gibbons, R. Leonard, C. Matthews, R. Oliver, M. Vickers, and M. Williams. 2001. Making better connections. Models of teacher professional development for the integration of information and communication technology into classroom practice. Canberra: Department of Education, Science \& Training.

Fisher, T., C. Higgins, and A. Loveless. 2006. Teachers learning with digital technologies: A review of research and projects. Futurelab Report no.14. http://www.futurelab.org.uk/ research/lit_reviews.htm\#lr14.

Gibson, J. 2008. Digital solution to age-old dilemma. Sydney Morning Herald, December 19-21.

Grundy, S., and J. Robison. 2004. Teacher professional development: Themes and trends in the recent Australian experience. In International handbook on continuing professional development of teachers, ed. C. Day and J. Sachs, 146-66. Maidenhead: Open University Press. 
Guba, E.G., and Y.S. Lincoln. 1981. Effective evaluation: Improving the usefulness of evaluation results through responsive and naturalistic approaches. San Francisco, CA: Jossey-Bass.

Guskey, T.R. 2002. Professional development and teacher change. Teachers and Teaching: Theory and Practice 8, nos. 3-4: 381-91.

Hargreaves, D. 1997. In defence of research for evidence-based teaching: A rejoinder to Martyn Hammersley. British Educational Research Journal 23, no. 4: 405-19.

Hartnell-Young, E., and N. Heym. 2008. How mobile phones help learning in secondary schools. Becta: Coventry.

Kearney, M., and S. Schuck. 2006. Spotlight on authentic learning: Student developed digital video projects. Australasian Journal of Educational Technology 22, no. 2: 189-208.

McFarlane, A., N. Rouche, and P. Triggs. 2007. Mobile learning: Research findings. Report for Becta. Coventry, UK: BECTA. http://partners.becta.org.uk/ index.php?section=rh\&catcode=_re_rp_02\&rid=14204.

McHale, T. 2005. Portrait of a digital native: Are digital-age students fundamentally different from the rest of us? Technology \& Learning 26, no. 2: 33-4

Miles, M., and M. Huberman. 1994. Qualitative data analysis. 2nd ed. Beverley Hills, CA: Sage.

Noddings, N., and C. Witherell. 1991. Epilogue: Themes remembered and forseen. In Stories lives tell: Narrative and dialogue in education, ed. C. Witherell and N. Noddings, 279-80. New York: Teachers College Press.

Naismith, L., P. Lonsdale, G. Vavoula, and M. Sharples. 2004. Literature review in mobile technologies and learning. Report 11. Futurelab Series. Bristol: Futurelab. http:// www.futurelab.org.uk/research/lit_reviews.htm\#lr11.

New South Wales Department of Education and Training (NSWDET). n.d. Professional Teaching Standards. Sydney: NSWDET. http://www.nswteachers.nsw.edu.au/IgnitionSuite/uploads/docs/18pp\%20PTSF\%20book\%20v6.pdf.

Partnership for 21st Century Skills. 2005. Road to 21st century learning: A policymaker's guide to 21 st century skills. Washington, DC: Author. http://www.21stcenturyskills.org/ images/stories/otherdocs/P21_Policy_Paper.pdf.

Peck, C., L. Cuban, and H. Kirkpatrick. 2002. Techno-promoter dreams, student realities. Phi Kappa Delta 83, no. 6: 472-80.

Phelps, R., A. Graham, and B. Kerr. 2004. Teachers and ICT: Exploring a metacognitive approach to professional development. Australasian Journal of Educational Technology 20, no. 1: 49-68.

Priest, A., and P. Sturgess. 2005. But is it scholarship? Group reflection as a scholarly activity. Studies in Learning, Evaluation Innovation and Development 2, no. 1: $1-9$

Richert, A. 1992. Voice and power in teaching and learning to teach. In Reflective teacher education: cases and critiques, ed. L. Valli, 187-97. Albany, NY: State University of New York Press.

Schön, D. 1987. Educating the reflective practitioner. San Francisco: Jossey-Bass.

Schuck, S. 2002. Walking the electronic tightrope: Questions surrounding infusion of IT into education subjects. In Improving student learning 9: Improving student learning using learning technology, ed. C. Rust, 186-94. Oxford: The Oxford Centre for Staff and Learning Development.

Schuck, S. 2003. Getting help from the outside: Developing a support network for beginning teachers. Educational Enquiry 4, no. 1: 49-67.

Sharples, M., J. Taylor, and G. Vavoula. 2005. Towards a theory of mobile learning. In Mobile technology: The future of learning in your hands, mLearn 2005, book of abstracts, 4th world conference on mLearning, ed. H. van der Merwe and T. Brown, 58, October 25-28, in Cape Town.

Sharples, M., R. Graber, C. Harrison, and K. Logan. 2008. E-safety and Web 2.0: Web 2.0 technologies for learning at Key Stages 3 and 4. Report 4 for Becta. Coventry, UK: BECTA.

Staples, A., M.C. Pugach, and D. Himes. 2005. Rethinking the technology integration challenge: Cases from three urban elementary schools. Journal of Research on Technology in Education 3, no. 3: 285-311. 
Swan, K., M. van 't Hooft, and A. Kratcoski. 2005. Uses and effects of mobile computing devices in K-8 classrooms. Journal of Research on Technology in Education 38, no. 1: 99-112.

Thomson, P., and H. Gunther. 2006. From 'consulting pupils' to 'pupils as researchers': A situated case narrative. British Educational Research Journal 32, no. 6: 839-56.

Wishart, J. 2009. Use of mobile technology for teacher training. In Mobile learning: Transforming the delivery of education and training, ed. M. Ally, 265-78. Edmonton, Canada: Athabasca University Press. http://www.aupress.ca/index.php/books/120155. 